\title{
Experimental and Numerical Simulation Investigation of Single-Phase Natural Circulation in a Large Scale Rectangular Loop
}

\author{
A.R. Antariksawan ${ }^{1^{\star}}$, S. Widodo ${ }^{2}$, M. Juarsa ${ }^{2}$, S. Ismarwanti ${ }^{3}$, D. Saptoadi ${ }^{4}$, \\ M.H. Kusuma ${ }^{2}$, T. Ardiyati ${ }^{5}$ and T.M.I. Mahlia ${ }^{6}$ \\ ${ }^{I}$ Center for Accelerator Science and Technology, National Nuclear Energy Agency, \\ Jl. Babarsari, Yogyakarta 55281, Indonesia \\ ${ }^{2}$ Center for Nuclear Reactor Technology and Safety, National Nuclear Energy Agency, \\ Puspiptek Area Serpong, Tangerang Selatan 15310, Indonesia \\ ${ }^{3}$ Center for Nuclear Fuel Technology, National Nuclear Energy Agency, \\ Puspiptek Area Serpong, Tangerang Selatan 15310, Indonesia \\ ${ }^{4}$ Heat Transfer Laboratory, Department of Mechanical Engineering, Universitas Indonesia, \\ Kampus UI Depok 16424, Indonesia \\ ${ }^{5}$ Center for Nuclear Facilities Engineering, National Nuclear Energy Agency, \\ Puspiptek Area Serpong, Tangerang Selatan 15310, Indonesia \\ ${ }^{6}$ School of Information, System and Modelling, Faculty of Engineering and Information Technology, \\ University of Technology Sydney, NSW, 2007, Australia
}

\section{ARTICLE INFO}

Article history:

Received 12 July 2017

Received in revised form 29 October 2018

Accepted 8 November 2018

Keywords:

Single-phase

Natural circulation

Passive system

RELAP5 code

\begin{abstract}
A B S T R A C T
In order to anticipate station blackout, the use of safety system based on passive features is highly considered in advanced nuclear power plant designs, especially after the Fukushima Dai-ichi nuclear power station accident. An example is the application of natural circulation in the emergency cooling system. To study the reliability of such an application, a research project on natural circulation was carried out. This paper describes the investigation results on the natural circulation phenomena obtained using a large rectangular experimental loop named FASSIP01. The experiments were conducted at two different heat source powers. The experimental results are analysed using existing correlation and numerical model simulation. The RELAP5 system code is applied to model the natural circulation. FLUENT computational fluid dynamic code is used to visualize the flow distribution. The experimental results show the establishment of stable natural circulation in all heat power input with the mass flow rate of about $0.0012 \mathrm{~kg} / \mathrm{s}$. Calculation using the existing correlation shows that the experimental Reynold numbers are lower than predicted by the correlation. The computational fluid dynamics-based tool could show the three dimensional distribution of the temperature, while the model of RELAP5 predict well the dynamic of the singlephase natural circulation established in the experimental loop. It is concluded that the stable natural circulation have been established in the large rectangular loop and the model of the RELAP5 could simulate the observed natural circulation phenomenon reasonably well.
\end{abstract}

(C) 2019 Atom Indonesia. All rights reserved

\section{INTRODUCTION}

Natural circulation (NC) is a fluid flow resulting from density difference. Such a circulation is induced by a heat source and a heat sink that are

${ }^{*}$ Corresponding author.

E-mail address: anhar@batan.go.id

DOI: https://doi.org/10.17146/aij.2019.762 located at different height levels instead of an external prime mover. The heated fluid, which has lighter density, will flow upward driven by the buoyancy force, and when it is cooled it will tend to flow downward due to gravity force. The merit of the deployment of the natural circulation system has been considered deeply in the new designs of nuclear power plants (NPPs) [1-3]. Such a natural circulation system is categorized as a passive system 
and is being considered to be used as cooling system in the NPP, both under normal and emergency operation. Not only in the NPP, the role of the passive system, including the natural circulation, is also of utmost importance for the safety operation of the research reactor [4-5]. The application of the natural circulation in the nuclear reactor involve many challenges; among other things, they include low driving forces, the pressure losses and the instability [1]. Therefore, deep understanding of the natural circulation characteristics in many circumstances is needed.

Vijayan [6] observed the general trends of the steady state and stability behavior of the singlephase natural circulation loop (NCL). The proposed correlation was applied to assess the experimental results of other researchers. It is concluded that the steady-state behavior of NCL can be expressed using non-dimensional Reynold number as a function of modified Grasshof number and the number representing geometry of the loop. Another study done by Sambudjian et al. [7] used the RELAP5 code to simulate natural circulation phenomena occuring in a rectangular loop experimental facility of $2600 \mathrm{~mm}$ height and $860 \mathrm{~mm}$ width. The simulation results agreed well with the experiment. Vijayan et al. [8] investigated the effect of loop diameter on the steady state and stability behavior of single- and two-phase NCLs. The experimental loop was a square loop with a $2100 \mathrm{~mm}$ height and a $1140 \mathrm{~m}$ width in vertical position. In the case of the single-phase loop, the small diameter was found more stable. An experimental study on NCL applied to the Advanced Pressurized Water Reactor was conducted by Lemos et al. [9]. A scaled-down facility, which is $1 / 10$ the size of the actual installation, was constructed. The experiment results have shown the behavior of the natural circulation in such small-scale system. A comprehensive review on advances in analysis and application of the single phase natural circulation in nuclear thermalhydraulic was conducted by Basu et al. [10]. It was indicated that the most fundamental issues of single phase NCL were explored, but their application in the nuclear thermal-hydraulic system were still to be explored. One-dimensional codes such as RELAP5 are commonly used, though they provide conservative results. Therefore, the use of threedimensional codes is likely to produce more realistic results. Saha et al. [11] investigated experimental and numerical analyses for an NCL under low and moderate heater power. The small-scale square natural circulation loop, $1 \mathrm{~m}$ long on each side, was mounted vertically. The work also studied the effect of ambient temperature. Numerical analyses were conducted using a MATLAB-based model, SIMULINK models, and RELAP5. Luzzi et al. [12] performed an assessment of analytical and numerical models on the experimental data obtained from a single-phase natural circulation in a vertical loop. This loop, named L2 NCL, consisted of square pipe of $1112 \mathrm{~mm}$ width and $988 \mathrm{~mm}$ height with the heater and cooler at the bottom and upper horizontal pipe, respectively. The developed model, which was based on the computation fluid dynamics, was able to capture the experimental data behavior. Other works were also conducted for application of natural circulation in specific NPP designs [13,14].

As part of the research program on the safety of NPP and considering the state of the art of the safety of light water reactor (LWR), the Center for Nuclear Reactor Technology and Safety (PTKRN) of BATAN has established a research program on the development of passive safety systems. The research is focused especially on the application of natural circulation for emergency cooling. This research program is carried out using experimental and numerical analysis approaches. One of the main experimental facility supporting the program is named FASSIP-01. This is a large rectangular NCL facility. The size of the facility is larger than the ones used in the other researches mentioned above. The facility is used to investigate fundamental characteristics of natural circulation. The current study aims to investigate the steady state characteristics of the single-phase natural circulation established in the FASSIP-01. The analysis of the experimental results with two different heater powers of 3.6 and $4.4 \mathrm{~kW}$ were carried out using the RELAP5 code and the computational fluid dynamic code, namely FLUENT. The objective of this study is to understand the fundamental characteristics of the single-phase natural circulation and to show the applicability the RELAP5 model for interpreting the experimental results. Previously, the preliminary investigation of the experimental result has been done [15]. It was found that the prediction by the RELAP5 showed discrepancies with the experimental results, especially on the prediction of the natural circulation mass flow rate. At present, the model has been improved. The result of this study is expected to contribute to the improvement of the data base on single-phase natural circulation, which in turn enabling the development of the passive safety system, especially the passive residual heat removal system in the NPP.

\section{METHODOLOGY}

\section{Experimental set up and procedure}

Figure 1 shows the schematic diagram of the facility with some temperature measurement locations. The rectangular NCL is made of 1 inch nominal pipe diameter (NPD) of stainless steel in 
rectangular form with $3500 \mathrm{~mm}$ width and $6000 \mathrm{~mm}$ height and $19000 \mathrm{~mm}$ total length. The piping is constituted of 34 sections of $500 \mathrm{~mm}$ length and two sections of $1000 \mathrm{~mm}$ length, for heated and cooled pipe part. Each section is joined with a flange. The heat source and the heat sink are located both at the vertical pipe, but on different sides. The heat source is comprised by a tank of 16 inch NPD of $800 \mathrm{~mm}$ height which is filled with water. Four electrical heaters of $5 \mathrm{~kW}$ each are located inside the tank. A venting pipe to the atmosphere is installed at the top of the tank, keeping the pressure in the heater tank at about $1 \mathrm{~atm}$. The heat sink is constructed from a water-filled tank with the same size as the heater tank. The water coolant is circulated from a refrigeration system of $1 \mathrm{hp}$ of capacity. The flow rate of the coolant could be varied by varying the motor frequency of the circulating pump. The inlet temperature of the coolant into the cooling tank varies slightly during the experiment depending on the heat exchanged in the refrigeration system, and it was approximately $8{ }^{\circ} \mathrm{C}$ when the steady state condition was achieved. An expansion tank is connected at the top of the upper horizontal pipe. The tank is partially filled with the water and connected to the ambient through a valve. The pipe from the outlet of the heater tank to the inlet of the cooling tank is called hot leg, and from the outlet of the cooling tank to the inlet of the heater tank is cold leg.

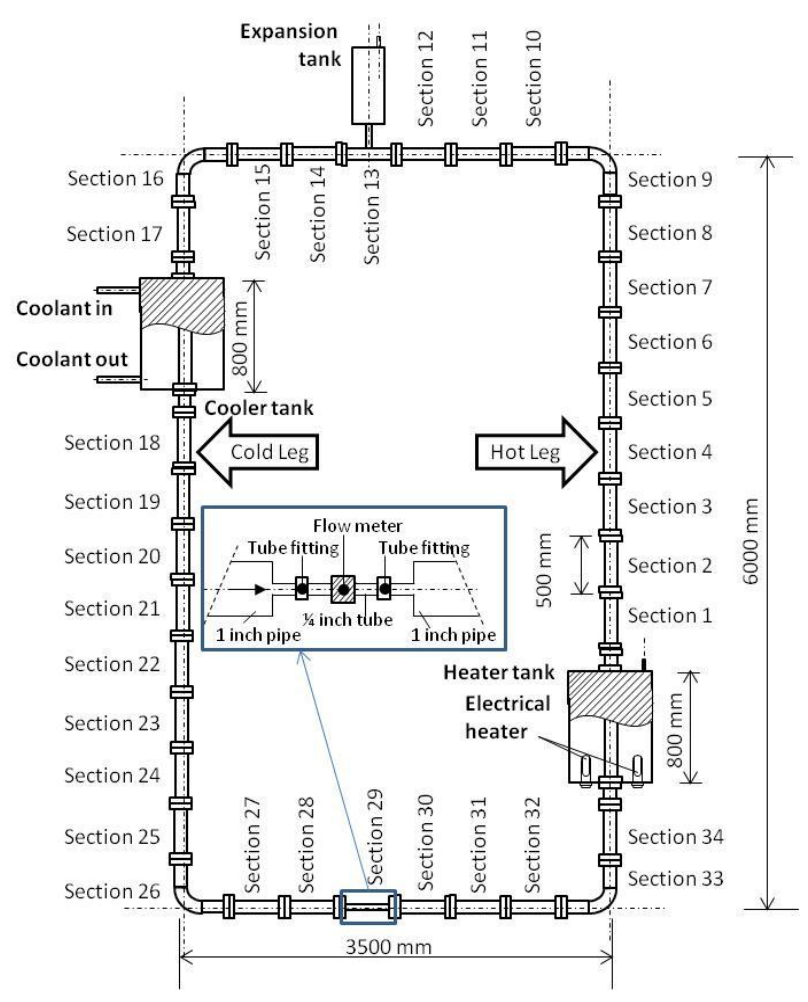

Fig. 1. Diagram of FASSIP-01 experimental loop.

The water temperature is measured using K-type thermocouples. Each thermocouple is located at mid length of each section. Other quantities measured were the pressure and the mass flow rate. All measurement are collected by the data acquisition system that is able to record up to one measurement per second.

The experiment is started by circulating the coolant water at the determined flow rate. The heating power is applied by increasing the voltage of the electrical heater step by step until the desired power is reached. While the heating power is increasing, the temperature of the water in the tank increases as well. The hot water transfers the heat to the water inside the rectangular loop pipe. At the cooling tank, the coolant removed the heat from the water inside the rectangular loop pipe. At some point, the natural circulation would be established steadily. The heating power remains during the 8-10 hours duration of the experiment.

\section{Computer codes}

This study uses the RELAP5 module of the RELAP5/SCDAP code, which is developed by the Innovative System Software [4]. The RELAP5 (Reactor Excursion and Leak Analysis Program) itself is developed by Idaho National Laboratory (INL) for United States Nuclear Regulatory Commission (USNRC) for modeling nuclear power plants. Initially, the code was used to model a smallbreak loss of coolant accident in a pressurized water reactor (PWR). Starting from RELAP1 version, the code has currently been developed into RELAP5-3D [16]. RELAP5 is now widely used for thermalhydraulic analyses of various types of installations, both nuclear and non nuclear $[5,17,18]$.

The RELAP5 code is a one-dimensional two-fluid thermal-hydraulic system code that models a complex system of hydrodynamic control volumes, heat structures, and components. The code equation set gives two-fluid simulation system using a non-equilibrium, non-homogeneous, six-equation representation. In term of the heat transfer model, the axial conduction could not be treated.

The FLUENT CFD code is also used in this study to provide the three dimensional figure of flow characteristic inside the rectangular loop pipe. The code is a commercal computational fluid dynamic software for modellinng fluid flow and heat transfer in various geometry. FLUENT solves conservation equations for mass and momentum. An equation for energy conservation is added for flow involving heat transfer.

\section{Model and calculation}

Figure 2 depicts the RELAP5 model for FASSIP-01 loop facility. While, the Table 1 shows the main component and the nodalization codes. 
All components of FASSIP-01 is modelled, except the refrigeration cooling system. The nodalization in heated and cooled pipe section are finer than the nodalization in other pipe sections. This is because of the higher temperature gradation in the region. The pipe wall and its insulation are also modelled with heat structure components. The last is also an improvement from the previous model [15].

Table 1. Nodalization of the FASSIP-01.

\begin{tabular}{llll}
\hline \multirow{2}{*}{ FASSIP-01 components } & Model & & \\
\cline { 2 - 4 } & Type & Number \\
\hline \multirow{2}{*}{ Hot leg } & Pipe & 103, & 104, \\
& & 107, & 110, \\
& & 111, & 200 \\
Cold leg & Branch & 109 & \\
& Pipe & 205, & 208, \\
& & 209, & 210, \\
Heater tank & Pipe & 211, & 100 \\
Cooler tank & Pipe & 300, & 315 \\
& TMDPVOL & 4100 & \\
\multirow{2}{*}{ Expansion tank } & TMDPJ & 401 & \\
& Pipe & 120 & \\
*TMDPVOL: time & Single volume & 700 & \\
junction & & &
\end{tabular}

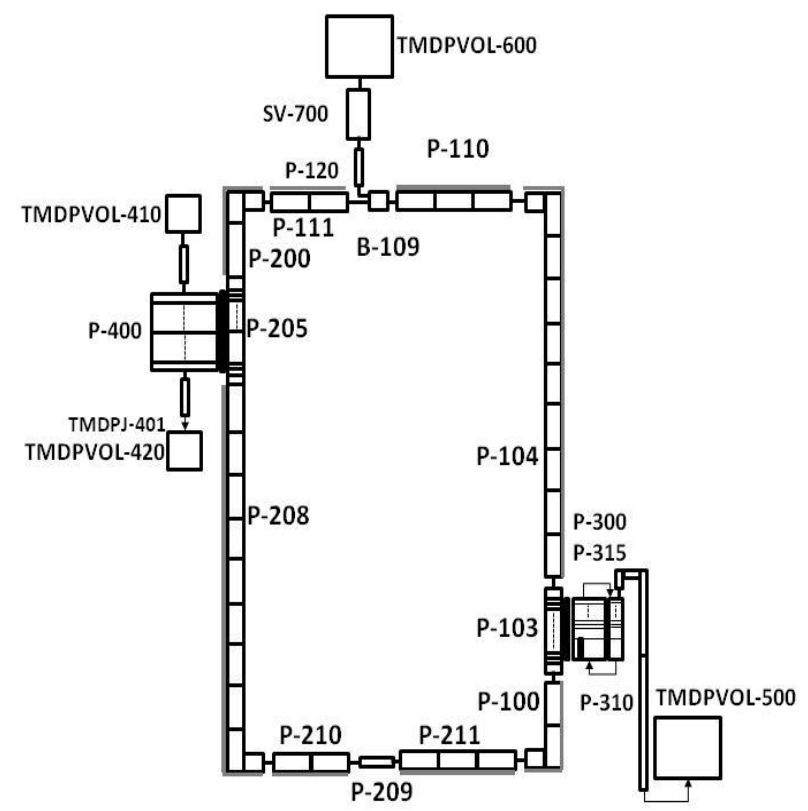

Fig. 2. RELAP5 Model and nodalization of FASSIP-01.

Two series of experiments have been performed so far, one without piping insulator and another with a rock wool pipe insulator. In each experiment, the electrical heater power and the mass flow rate of the water coolant were two main variables. For the present study, two experiments with different heater power inputs, i.e., $3.6 \mathrm{~kW}$ and $4.4 \mathrm{~kW}$, are going to be discussed. Both experiments had the same coolant mass flow rate of $10 \mathrm{lpm}$ and with pipe insulator.

\section{RESULTS AND DISCUSSION}

\section{Experimental results}

The results for $3.6 \mathrm{~kW}$ input power have been partly discussed in [15]. Regarding the pipe insulator, the experimental results of Saha et al. [11] showed that the ambient temperature had an influence on the stability of the natural circulation inside the pipe. Therefore, to reduce the effect of the ambient boundary condition, the evaluation in this study is done at the same condition by implementing the pipe with insulator.

Figure 3 shows the water temperature in several locations along the hot leg of the rectangular loop pipe. The temperature of the water in section 1 , which is the closest to the heated pipe section, increased first. At about $10000 \mathrm{~s}$ the temperature at section 1 reached the steady state of about $100{ }^{\circ} \mathrm{C}$ as it is adjacent to water fille heater tank that boils at about $1 \mathrm{~atm}$. At other locations along the hot leg, the water temperature rises subsequently following the increase of the section 1 temperature; the closer the location to the heater, the sooner the temperature increases. At the initial period, the temperature increases more slowly. This is due to the heat diffusion. Once the buoyancy force overcomes the gravitational and the friction, the water flowed and the temperature increased faster until steady state was reached.

A similar pattern of temperature distribution has been found in the case of the heater power input of $4.4 \mathrm{~kW}$ as shown in Fig. 4. The reason is that the heat source of both cases are at the same temperature. As indicated earlier the heater tank is connected with a venting pipe to the ambient, so the pressure in the heater tank is always approximately 1 atm. On the other hand, the expansion tank connected to the rectangular loop pipe is also opened to the atmosphere. However, at the higher input power, i.e., $4.4 \mathrm{~kW}$, the temperature increased more rapidly and the steady state was attained earlier than is the case for the $3.6 \mathrm{~kW}$ input power.

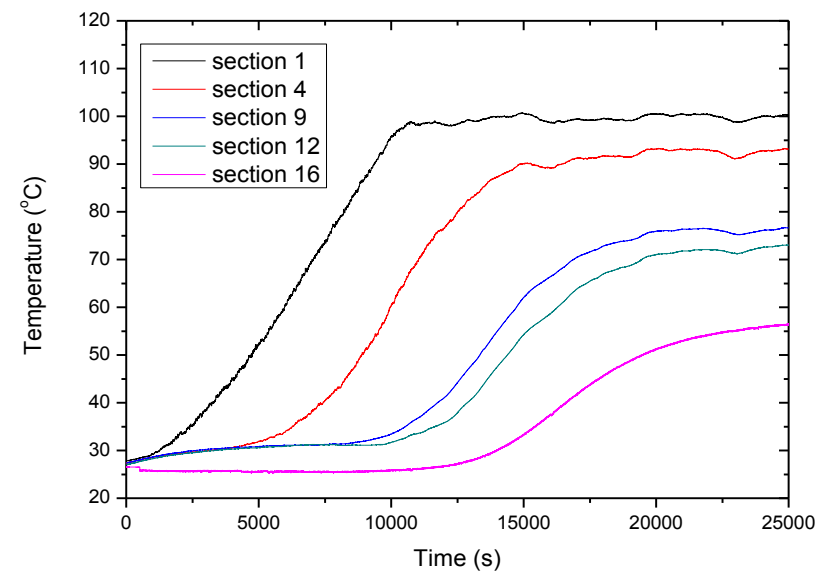

Fig. 3. Temperature distribution at the hot leg $(3.6 \mathrm{~kW}$ input power). 


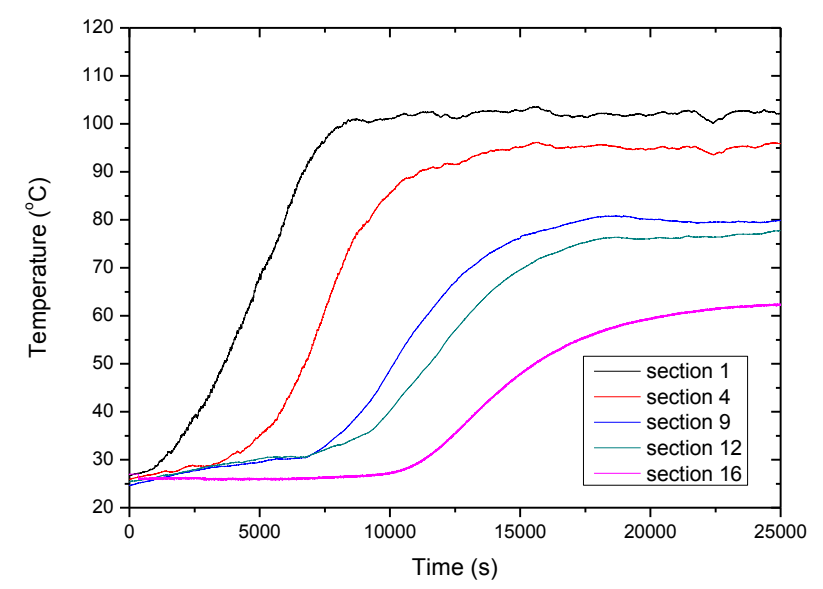

Fig. 4. Temperature distribution at the hot leg $(4.4 \mathrm{~kW}$ input power).

Regarding the induced $\mathrm{NC}$ mass flow rate, Fig. 5 shows the evolution of the NC mass flow rate established in the rectangular loop pipe for $3.6 \mathrm{~kW}$ and $4.4 \mathrm{~kW}$ input power. Comparing both cases, the mass flow rate for $4.4 \mathrm{~kW}$ input power, i.e., $0.0013 \mathrm{~kg} / \mathrm{s}$, is only slightly higher than the $0.0012 \mathrm{~kg} / \mathrm{s}$ for $3.6 \mathrm{~kW}$ input power. The difference is small because the $\mathrm{NC}$ is driven by the temperature of the heating water, and that temperature in both cases is approximately the same, i.e., the saturation temperature for approximately $1 \mathrm{~atm}$. The difference is only on the time of the steady state is achieved; with the higher input power, it is achieved more quickly. The mass flow rate is quite low. The theoretical and numerical prediction without considering those singularities resulted in a higher mass flow rate as found in the previous works [15-19].

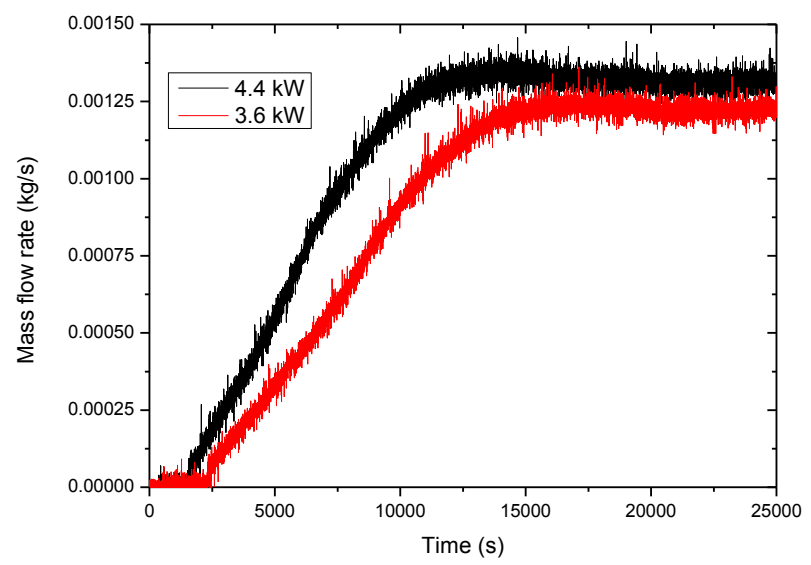

Fig. 5. The mass flow rate in the rectangular loop for two different heat input.

Vijayan [6] proposed a non-dimensional correlation for NCL steady state as follows:

$$
R e_{s s}=C\left(\frac{G r_{m}}{N_{G}}\right)^{r}
$$

where:

$$
\begin{aligned}
& G r_{m}=\frac{\bar{D}_{r}^{g} \rho_{b}^{2} \beta g \Delta T_{r}}{\mu^{2}} ; \Delta T_{r}=\frac{Q_{h} H}{\bar{A}_{r} \mu C p^{2}} ; \\
& \operatorname{Re}_{s s}=\frac{\bar{D}_{r} W_{S S}}{\bar{A}_{r} \mu}, \\
& N_{G}=\frac{\bar{L}_{t}}{\bar{D}_{r}} \sum_{i=1}^{N}\left(\frac{l_{\text {eff }}}{D^{1+b_{A}} A^{2-b}}\right)_{i}
\end{aligned}
$$

with $C$ and $r$ are 0.1768 and 0.5 for laminar flow, and 1.96 and $1 / 2.75$ for turbulent flow, respectively.

Applying the above correlation for nonuniform diameter loop with the data of the experimental loop geometry and conditions of the current study produced the result presented in Fig. 6 . There are two experimentally-obtained data points representing two results using two different data of temperature difference across heater and cooler pipe. In both cases, the results are not well matched with the correlation of Vijayan [6]. This is most probably because of high singular (minor) pressure losses at the piping section where the flow meter is located. That section is a tube of 1 inch outer diameter, $500 \mathrm{~mm}$ length, with abrupt connections at the inlet and outlet side. The flow meter is a turbine flow meter type placed and connected at the midsection using tube fittings. For the geometry and experimental conditions, the assumption taken for deriving the correlation [6] may not be valid. It may need further investigation to comprehend that matter. It should also be noted that in the experimental results there were different temperature differences between heater and cooler that might be caused by the heat losses along the hot leg.

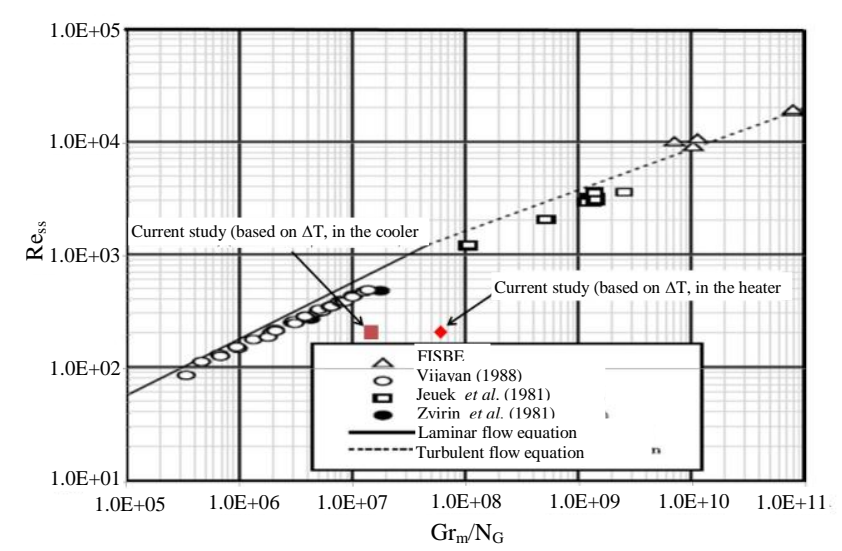

Fig. 6. Steady state natural circulation loop flow in non-uniform diameter loop (the curve and data in the curve are taken from [6]).

\section{RELAP5 simulation}

The model and nodalization shown in Fig. 2 was applied for simulating the experiment with the input power of $3.6 \mathrm{~kW}$. Figure 7 shows the temperature distribution at different section of the 
hot leg and the heater tank, while Fig. 8 depicts the water mass flow rate in the rectangular loop pipe for $50000 \mathrm{~s}$ duration of calculation. Those results show that the steady state condition has been achieved. As observed also in the experiment (see Fig. 3), the temperature of the section 1 increased fastest and reached the steady-state temperature at about $10000 \mathrm{~s}$. The temperature of the subsequent sections increased accordingly and reached the steady-state temperature more slowly at lower temperatures than section 1 , which is the closest to the heated pipe section, while the evolution of the mass flow rate is also similar to the experiment (see Fig. 5), except for the slower rate of increase.

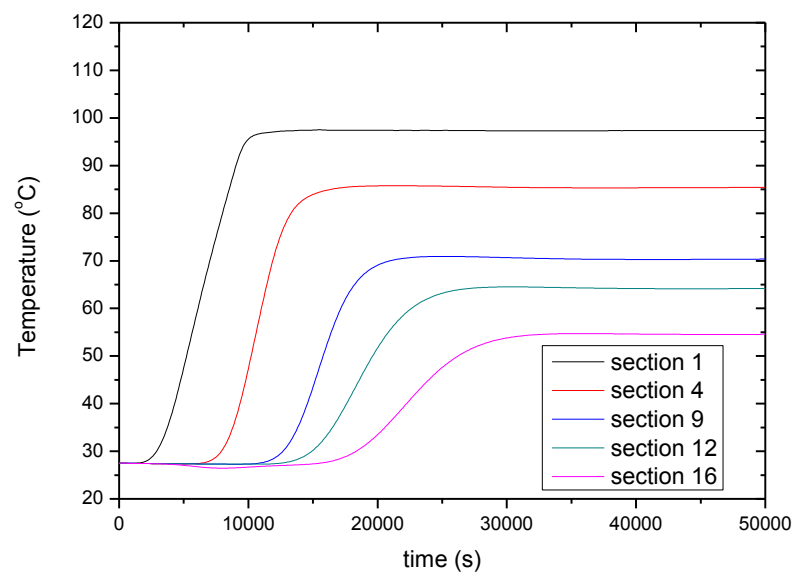

Fig. 7. The temperature distribution in hot leg.

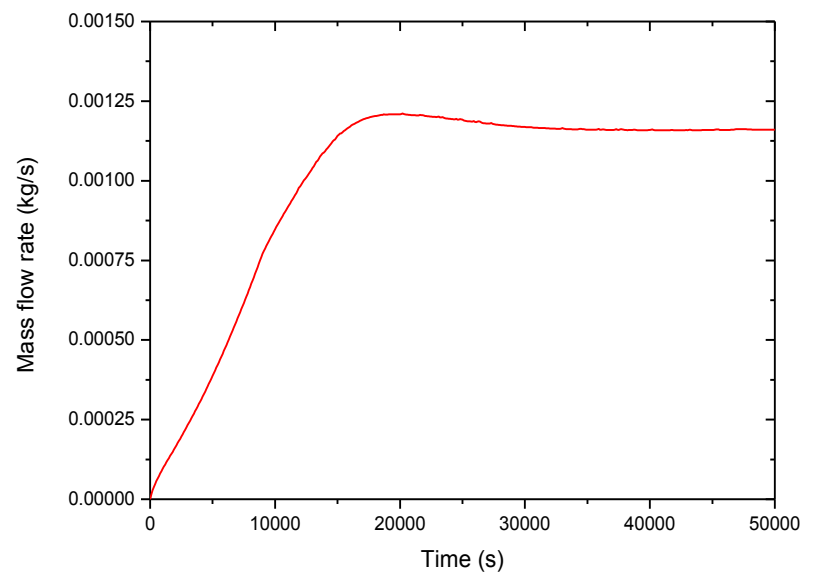

Fig. 8. Mass flow rate in rectangular loop pipe.

The heated pipe section and the heater tank water temperature are depicted in Fig. 9. The water temperature in the heater tank increased to the saturation temperature following the heat absorbed from the electrical heater. The water temperature in the heated pipe section also increased following the temperature increase in the heater tank. At the outlet, the water temperature in the pipe is close to the temperature of the heater tank, i.e., about $100{ }^{\circ} \mathrm{C}$.
The comparison of the experimental results and the calculation for the water mass flow rate is shown in Fig. 10. As shown, the calculated water mass flow rate is in good agreement with the measurement. In both, the steady-state mass flow rate is about $0.0012 \mathrm{~kg} / \mathrm{s}$.

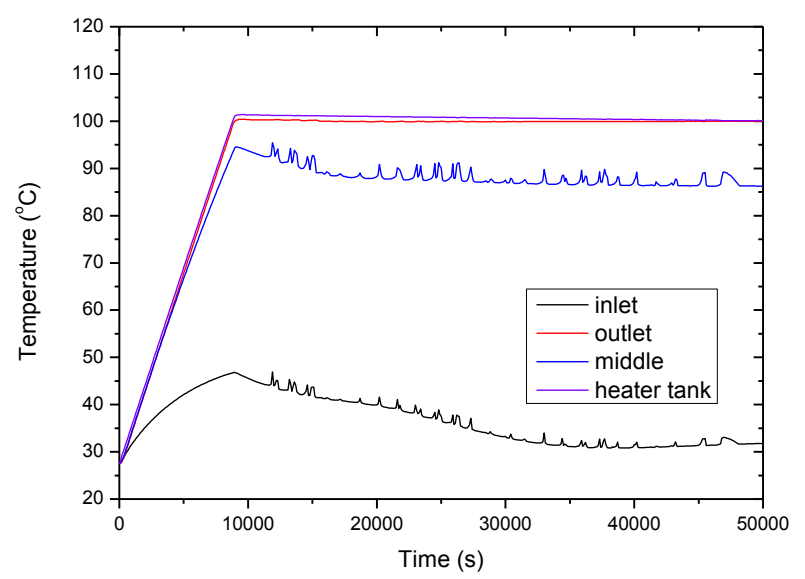

Fig. 9. Temperature evolution in the heated pipe section and in the heater tank.

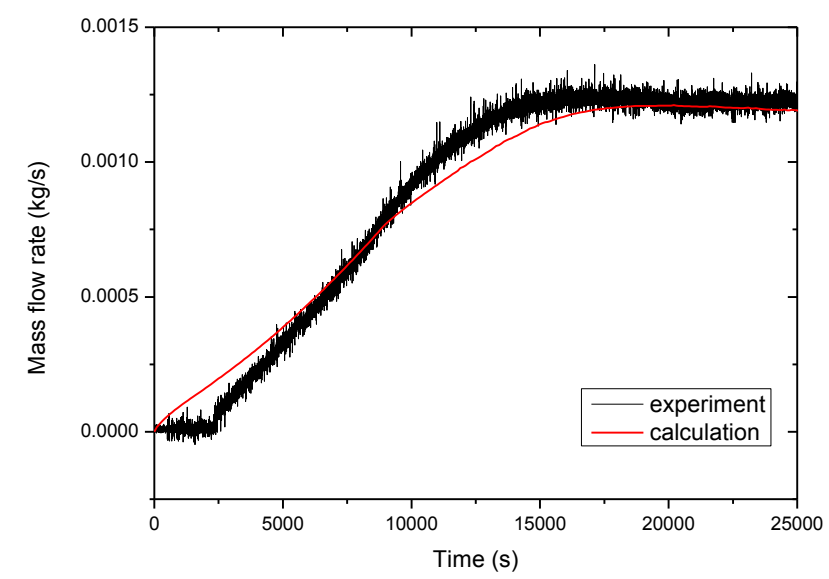

Fig. 10. Comparison of mass flow rate; measurement vs calculation.

On the other hand, Fig. 11 shows the comparison of the evolution and distribution of the water temperature in the hot leg. The temperature profiles for section 1 and 4 are quite similar, but for other sections, the predicted temperature are lower than the measured from the experiment. The transient period from the calculation is longer than at the experiment. The calculated temperature of section 16, despite showing a lower rate, is close to the measurement at the steady state (at about 32000 s). Table 2 summarizes the steady state temperature data for both the measurement and the calculation. The average relative difference is approximately $7 \%$.

The difference between calculation and experimental results are probably due to the model of the heat loss to the environment and the flow at the junction of each pipe section where the junction 
was not smooth. Another possibility is that the model cannot consider the effect of the axial heat conduction in the pipe wall.

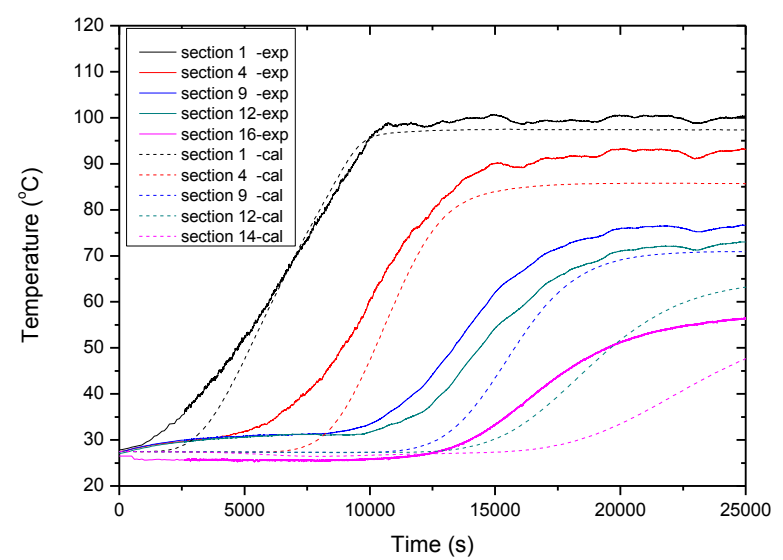

Fig. 11. Temperature distribution: measurement vs. calculation.

Table 2. Comparison of the steady state temperature between measurement and calculation.

\begin{tabular}{|c|c|c|c|}
\hline \multirow{2}{*}{$\begin{array}{l}\text { Pipe } \\
\text { section }\end{array}$} & \multicolumn{2}{|c|}{ Temperature $\left({ }^{\circ} \mathrm{C}\right)$} & \multirow{2}{*}{$\begin{array}{l}\text { \% relative } \\
\text { difference }\end{array}$} \\
\hline & Measurement & Calculation $^{\mathrm{a}}$ & \\
\hline Section 1 & 100.3 & 97.38 & 2.9 \\
\hline Section 4 & 93.1 & 85.41 & 8.2 \\
\hline Section 9 & 76.7 & 70.36 & 8.2 \\
\hline Section 12 & 73.1 & 64.17 & 12.2 \\
\hline Section 16 & 56.7 & 54.56 & 3.8 \\
\hline
\end{tabular}

It should be noted that in the model, considering the above experimental results analyses, one variable that had been adjusted to predict the measurements well is the friction losses coefficient in the flow meter tube section. A study by Zweibaum [20] showed that the friction loss coefficient in several types of component, such as coriolis flow meter at the low Reynold number, could increase. Therefore, in this study, for regular piping the existing analytical correlations were used and adjusted friction loss was applied at the flow meter and the related tube section. The experimental study on the pressure loss of the flow meter component would be helpful to improve the model.

\section{CFD simulation}

The one-dimensional calculation results as obtained from the RELAP5 cannot be used to investigate the radial profile of the flow inside the pipe. Thus, to better understand the characteristics of the natural flow in the rectangular loop pipe, the analysis using CFD code is performed. Such an analysis using a three-dimensional code would facilitate a more realistic assessment, as recommended by [10]. At the present work, the analysis using CFD is still at the preliminary stage and is aimed solely to explore the temperature distribution in a simplest model, especially at the hottest part. Figure 12 shows the three-dimensional temperature distribution of the water inside the rectangular loop pipe at the steady state. The boundary conditions at the inlet pipe side are the temperature and the mass flow rate obtained from the experiment (with $3.6-\mathrm{kW}$ input power). As shown in the figure, the temperature profile changes along the pipe. At the inlet, the temperature is homogenously at high temperature. While the water flows upward, the temperature in the upper part starts increasing from its initial temperature, but at the same time the heat losses to the environment occurs through the pipe wall and the insulator. It results in the temperature at the center being higher than at the wall side. As the diameter of the pipe is relatively small and the velocity is quite low, the temperature gradient in the radial direction is small. Figure 13 presents the axial water temperature distribution at the center line of the hot leg. At the first meter of the hot leg pipe, the temperature decreases by about $8{ }^{\circ} \mathrm{C}$. It is quite close to the RELAP5 calculation results and has a similar linear trend to the temperature decrease obtained from the experiment (see insert in Fig. 13).

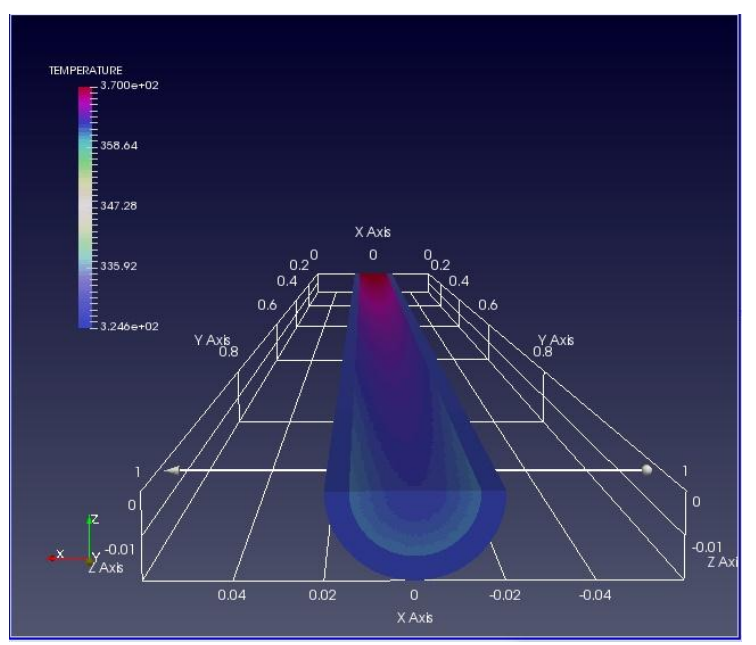

Fig. 12. Temperature distribution in straight hot leg.

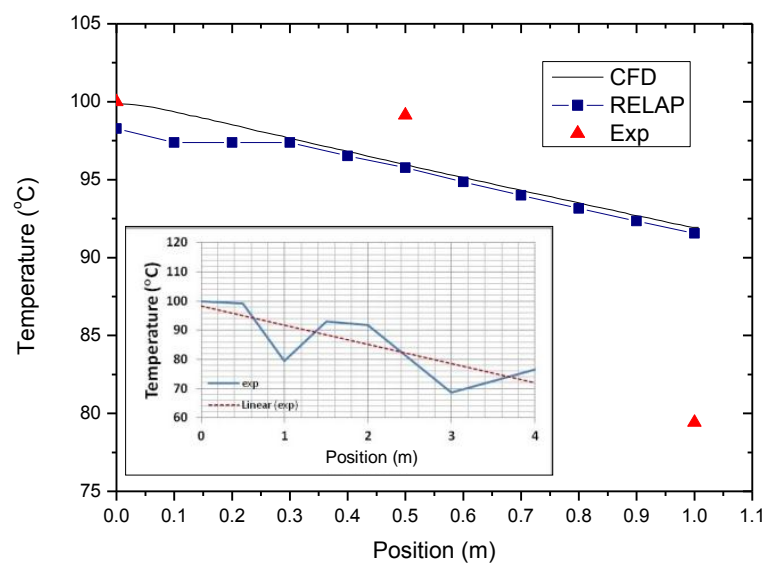

Fig. 13. The axial water temperature distribution in first $1 \mathrm{~m}$. 


\section{CONCLUSION}

A steady and stable single-phase natural circulation was observed at a large rectangular loop, FASSIP-01, for different input powers. The mass flow rate was influenced by the friction losses from the piping and the components in the loop. Considering the experimental set-up, variation of the input power did not affect the characteristic of the natural circulation, except the duration to achieve the steady state. On the other hand, the RELAP5 model could be validated against the experimental results by predicting the mass flow rate and the water temperature distribution, with a good agreement. Regarding the experimental facility, it is recommended to redesign the heater section in order to provide the specified heat flux source and to ensure the uniformity of the diameter of the loop.

\section{NOMENCLATURE}

$\begin{array}{ll}A & \text { dimensionless flow area, } \frac{A}{A_{r}} \\ b & \text { constant in Eq. (1) } \\ C & \text { constant in Eq. }(1) \\ C p & \text { specific heat }(\mathrm{J} / \mathrm{kg} / \mathrm{K}) \\ \bar{D} & \text { hydraulic diameter }(\mathrm{m}) \\ D & \text { dimensionless hydraulic diameter, } \frac{\bar{D}}{\bar{D}_{r}} \\ g & \text { gravitational acceleration }(\mathrm{m} / \mathrm{s}) \\ G r_{m} & \text { modified Grashof number defined by Eq. }(1 \mathrm{a}) \\ H & \text { loop height }(\mathrm{m}) \\ \bar{L} & \text { length }(\mathrm{m}) \\ N & \text { number of pipe segment } \\ N_{G} & \text { dimensionless parameter defined by Eq. }(1 \mathrm{c}) \\ Q & \text { total heat input rate }(\mathrm{W}) \\ r & \text { constant in Eq. }(1) \\ R e & \text { Reynolds number, } \bar{D}_{r} W / \bar{A}_{r} \mu \\ T & \text { temperature }(\mathrm{K}) \\ \Delta T & \text { temperature difference }(\mathrm{K}) \\ W & \text { mass flow rate }(\mathrm{kg} / \mathrm{s}) \\ G r e e & \text { symbols } \\ \beta & \text { thermal expansion coefficient }(1 / \mathrm{K}) \\ \mu & \text { dynamic viscosity }\left(\mathrm{Ns} / \mathrm{m}^{2}\right) \\ \rho_{0} & \text { reference density }\left(\mathrm{kg} / \mathrm{m}^{3}\right)\end{array}$

\begin{tabular}{ll}
\multicolumn{2}{l}{ Subscripts } \\
cal & calculation \\
eff & effective \\
$\mathrm{h}$ & heater \\
$i$ & $i^{\text {th }}$ segment \\
meas & measurement \\
$r$ & reference value \\
ss & steady state \\
$\mathrm{t}$ & total
\end{tabular}

\section{ACKNOWLEDGMENT}

The research was conducted at PTKRN BATAN. The authors acknowledge the support of BATAN through the budget from the DIPA-PTKRN 2017 and the IAEA through Research Contract No: 20948 as part of the IAEA Coordinated Research Project I32010. They also express their gratitude to Giarno and colleagues from the Experimental Thermal-hydraulic Subdivision for the supporting experimental data.

\section{REFERENCES}

1. H. Hidayatullah, S. Susyadi and M.H. Subki, Prog. Nucl. Energy 79 (2015) 127.

2. M. Karol, T. John and J. Zhao, Renew. Sustain. Energy Rev. 44 (2015) 643.

3. H. Nawaz, M. Ilyas, M. Ahmad et al., Ann. Nucl. Energy 98 (2016) 191.

4. A.R. Antariksawan, S. Widodo and H. Tjahyono, Journal of Nuclear Reactor Technology Tri Dasa Mega 19 (2017) 59. (in Indonesian)

5. A.R. Antariksawan, E. Umar, S. Widodo et al., Int. J. Technol. 18 (2017) 698.

6. P.K. Vijayan, Nucl. Eng. Des. 215 (2002) 139.

7. G. Sambudjian, D.A. de Dandrade, P.E. Umbehaun et al., J. Braz. Soc. Mech. Sci. Eng. XXXIII (2011) 227.

8. P.K. Vijayan, A.K. Nayak, D. Saha et al., J. Sci. Technol. Nucl. Install. 2008 (2008) 1.

9. W.F. Lemos, J. Su and J.L.H. Faccini, Experimental study of natural circulation circuit, Proc. Int. Nucl. Atlantic, Conf (2011) 1.

10. D.N. Basu, S. Bhattacharyya and P.K. Das, Nucl. Eng. Des. 280 (2014) 326.

11. R. Saha, S. Sen, S. Mookherjee et al., J. Heat Transfer 137 (2015) 1.

12. L. Luzzi, M. Misale, F. Devia et al., Chem. Eng. Sci. 162 (2017) 262.

13. H. Xiaofan, S. Zhongning and L. Wenjing. Ann. Nucl. Energy 109 (2017) 612.

14. Y. Chung, H. Park, W. Lee et al., Ann. Nucl. Energy 77 (2015) 402.

15. A.R. Antariksawan, S. Widodo and M. Juarsa et al., Preliminary Investigation of Natural Circulation Stability in FASSIP-01 Experimental Facility using RELAP5 Code, Proceeding of the 9th International Conference on Thermofluid 2017 (2018). 
16. G.L. Mesina, Nucl. Sci. Eng. 182 (2016) v.

17. M.H. Kusuma, N. Putra, A.R. Antariksawan et al., Nucl. Eng. Technol. 49 (2017) 476.

18. M.H. Kusuma, N. Putra, A.R. Antariksawan et al., Int. J. Therm. Sci. 126 (2018) 162.
19. H. Tjahyono, Atom Indonesia 43 (2017) 157

20. N. Zweibaum. Experimental Validation of Passive Safety System Models: Application to Design and Optimization of Fluoride-SaltCooled, High-Temperature Reactors, Ph.D. Thesis, University of California (2015). 